\title{
Comparative Analysis on Regional (NCAAA) and International (ABET) Accreditation for Mechanical Engineering Program
}

\author{
Ibrahim M Alarifi ${ }^{1,2 *}$ \\ ${ }^{1}$ Department of Mechanical and Industrial Engineering, Majmaah University, Saudi Arabia \\ ${ }^{2}$ Engineering and Applied Science Research Center, Majmaah University, Saudi Arabia
}

Submission: February 04, 2021; Published: February 15, 2021

"Corresponding author: Ibrahim M Alarifi, Department of Mechanical and Industrial Engineering \& Engineering and Applied Science Research Center, College of Engineering, Majmaah University, Al-Majmaah 11952, Riyadh, Saudi Arabia

\begin{abstract}
The mechanical engineering department of Majmaah University was being upgraded for ABET accreditation from 2017 to 2019. The quality appraisal by an autonomous agency is the requirement for the accreditation of the university. Accreditation can be obtained either for the entire institution or for individual programs within an institution. Universities request accreditation agencies to assess their programs, faculty, and students' achievement, whether they comply with the criteria set for higher educational institutions. The organization is regularly reassessed and accredited to ensure compliance with standards. Therefore, the study aims to identify the effectiveness and efficiency of two accreditation systems. Majmaah University had been upgrading it's academic as well as non-academic infrastructure for both regional (National Commission for Academic Accreditation and Assessment-NCAAA) and international (Accreditation Board for Engineering and Technology-ABET) accreditation; afterward, the ME program was recognized by international (ABET) accreditation two years ago. The study showed that criteria and standards for academic assessment and accreditation were determined by establishing NCAAA in Saudi Arabia. The management and quality of educational institutions under the highest international standards were ensured by focusing on higher studies institutions' quality assurance procedures. However, the study results revealed a lack of awareness of professional and ethical responsibility because of the absence of any ethical course in the curriculum of ME, as noticed by Mechanical Engineering program mapping.
\end{abstract}

Keywords: Engineering; Technology; Academic accreditation; KPIs codes; Program educational objectives

Abbreviations: ABET: Accreditation Board for Engineering and Technology; NCAAA: National Commission for Academic Accreditation and Assessment; SAQF: Saudi Arabia Qualifications Framework

\section{Introduction}

Since schools and colleges seek accreditation and emphasize their accomplishments, there is a need to explore this concern in detail. This study answers the following questions: What does it mean to be accredited? How is this reflected in the programs? What accredited programs share commonly? The idea of quality assurance has emerged with the expansion of the post-secondary institution concerning formats and numbers such as conventional versus online or distance education. This can be accomplished via internal or external bodies such as international, national, professional, and regional.

The quality of the institution's program is to be identified based on predefined criteria or standards. This will assist the institution in improving its programs, reputation, and environment, facility by benchmarking with other international and regional schools [13]. Evaluating the program consequences is not an easy task. It is a tedious and continuous process. In particular, it needs integrating quality factors concerning the details of the program. Postsecondary programs are accredited through the Accreditation Board for Engineering and Technology in computing, engineering, applied science, and engineering technology. The Council for Higher Education Accreditation (CHEA) has identified ABET since 1997.

ABET accreditation is an international standard in STEM education. Graduating from an Accreditation Board for 
Engineering and Technology (ABET)-accredited program means students will surely be able to secure a job in computing and engineering, and natural and applied sciences. Several countries have accepted ABET accreditation, and internationally, employers recognize ABET-accredited programs' value. Employers seek to find professionals who can handle complex environments and prosper [4].

ABET accreditation ensures that the relevant programs meet quality standards and produce graduates capable of joining the global workforce. Additionally, ABET plays an essential role in ensuring the quality of education for professionals who, in return, play their part in resolving global challenges. National Commission for Academic Accreditation and Assessment (NCAAA) was established in Saudi Arabia to shape criteria and standards for academic assessment and accreditation. The commission focuses on higher learning institutions' quality assurance system to ensure that educational institutions' management and quality are at par with the highest international standards. Figure 1 shows the results of quality and skills development, which acquired a $75 \%$ satisfaction level.

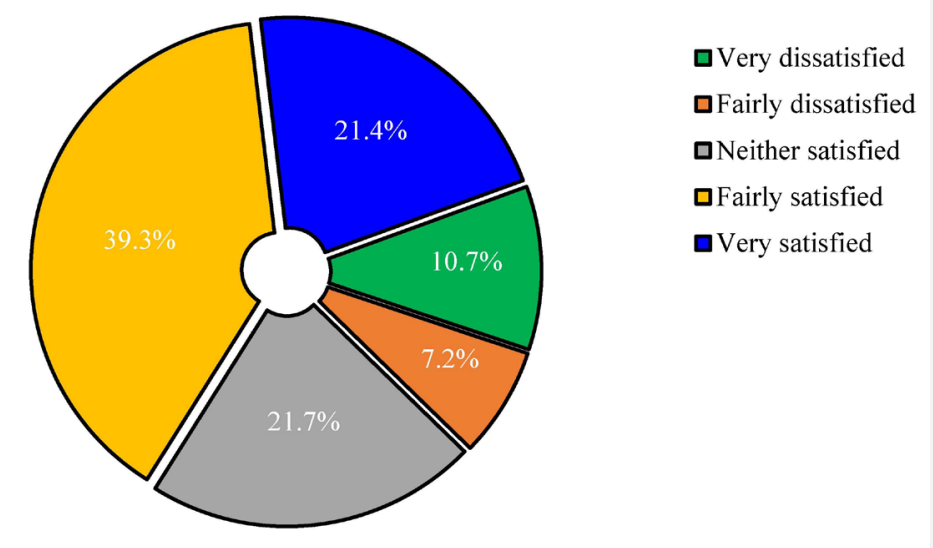

Figure 1: Quality and skills development results.

The two accreditation bodies undertake the accreditation of engineering courses and institutions of Saudi Arabia. Mechanical engineering involves applying engineering principles, basic sciences, mathematics, and technology to design, control, and construct machines to develop the quality of life. Students of mechanical engineering acquire skills and knowledge of Electromechanical Systems and Control, Manufacturing and Materials Science, Thermal and Fluids, Design, and Analysis of Mechanical Systems. Majmaah University has dedicated faculty and staff to ensure mechanical engineering quality to meet or surpass the accreditation bodies' quality standards. The engineering department is well-equipped and often organizes industrial training and visits to strengthen students' learning process and understanding. The current study aims to distinguish between ABET and NCAAA by identifying the accreditation prerequisite requirements and standards in a similar context.

There is restricted literature that discusses how to enhance the learning process as well as conceptual understanding of assessment and ABET accreditation in different disciplines systematically while the literature provides different research related to it [5-11]. For example, the majority of these contributions emphasize the ABET accreditation experience at an intellectual level regardless of going comprehensively or stressing only one element of the ABET criteria, such as continuous enhancement or evaluation mechanism [12]. Thereby, this paper emphasizes the recently approved revisions to ABET-CAC criteria that integrate to information systems programs. This study intends to share the Engineering department at Majmaah University with the new ABET-CAC standards.

\section{Literature Review}

Numerous options are available for young college students to choose as their career. However, accreditation of the institution is one of the key factors to be considered in the process. Accreditation means that a self-governing agency assesses the institution under consideration for quality. Accreditation can be obtained either for the entire institution or individual programs within an institution. Institutional accreditation is a voluntary process that institutions go through. Universities request accreditation agencies to assess their programs, faculty, and students to ascertain whether they meet higher education [13]. Once the standards are verified, the institution is regularly reassessed and accredited to ensure that the whole institution continues to meet standards. Particularly, accreditation is essential for engineering universities.

Engineering programs and other courses such as medical specialties, education, and psychology, often require an 
independent accreditation of the courses. Program-based certification is the purview of professional agencies focusing on a specific study domain. ABET makes sure that the study's curriculum meets the prerequisite requirements [14]. On the other hand, NCAAA academic accreditation and assessment encourages, supports, and evaluates Saudi Arabia universities' quality assurance procedures.

\section{Regional (NCAAA) Vs National (ABET) Accreditation}

Table 1 shows the different NCAAA Domains of Learning and ABET outcomes. NCAAA domains include knowledge, interpersonal skills, cognitive skills, obligation, psychomotor, numerical, and communication technology skills. The knowledge domain assesses the capability to recollect and communicate information. The domain of intellectual skills assesses the ability to use principles and concepts in problem-solving and thinking. The domain of relational skills and accountability assesses the capacity to take responsibility for their education and moral and ethical growth. Psychomotor skills are essential in some education fields and are measured as a supplementary domain in some programs. The domain of communication information technology and numerical skills assesses basic communication and mathematical abilities.

Table 1: NCAAA VS. ABET student learning outcomes codes.

\begin{tabular}{|c|c|c|c|}
\hline \multirow{2}{*}{ Domain } & \multicolumn{2}{|c|}{ Code } & \multirow{2}{*}{ Learning Outcomes } \\
\hline & ABET & NCAAA & \\
\hline \multirow{3}{*}{ A. Acknowledge } & (h) & a1 & $\begin{array}{l}\text { The broad education is necessary to understand the impact of engineering solutions globally, } \\
\text { economic, environmental, and societal context. }\end{array}$ \\
\hline & (j) & $\mathrm{a} 2$ & A knowledge of contemporary issues. \\
\hline & (b) & b1 & An ability to design and conduct experiments, as well as to analyze and interpret data \\
\hline \multirow{3}{*}{ B. Cognitive Skills } & (c) & b2 & $\begin{array}{l}\text { An ability to design a system, component, or process to meet desired needs within realistic } \\
\text { constraints }\end{array}$ \\
\hline & (e) & b3 & An ability to identify, formulate, and solve engineering problems \\
\hline & (d) & $\mathrm{c} 1$ & An ability to function on multidisciplinary teams \\
\hline \multirow{2}{*}{$\begin{array}{l}\text { C. Interpersonal Skills \& } \\
\text { Responsibility }\end{array}$} & (f) & $\mathrm{c} 2$ & An understanding of professional and ethical responsibility \\
\hline & (i) & c3 & A recognition of the need and an ability are to engage in life-long learning. \\
\hline \multirow{3}{*}{$\begin{array}{l}\text { D. Communication, } \\
\text { Information Technology, } \\
\text { Numerical }\end{array}$} & (a) & d1 & An ability to apply knowledge of mathematics, science, and engineering \\
\hline & (g) & $\mathrm{d} 2$ & An ability to communicate effectively \\
\hline & $(\mathrm{k})$ & d3 & $\begin{array}{l}\text { An ability to use the techniques, skills, and modern engineering tools is necessary for engineer- } \\
\text { ing practice. }\end{array}$ \\
\hline
\end{tabular}

In Saudi Arabia, technological and engineering programs are competing to attain the most internationally recognized accreditation system, ABET. The accreditation process focuses on students' achievements and the quality of teaching measured through performance indicators during direct and indirect assessments. These assessments relate to students' outcomes recorded in the Program Educational Objectives course portfolios and other significant criteria that call for a Self-Study Report presentation. In the Faculty of Engineering, Engineering programs provide individuals a learning experience that enables them to build up the abilities and skills to match NCAAA and ABET requirements.

In the case of NCAAA, student outcomes and other added results that might be expressed via the ME program are adopted as the course's educational objectives. The educational management in the faculty of engineering develops a measurement and assessment process that regularly evaluates the level of accomplishment in terms of students' results compared to the five domains of learning stipulated by the NCAAA. For engineering programs, the psychomotor domain is not applicable. All ABET outcomes demand a higher level of learning in the engineering subjects compared to knowledge. Minimum Level 3 of the cognitive domain of Bloom's taxonomy is necessary. Acquaintance with discipline-related industrial practices is also necessary and is accomplished through summer training activity.

ABET accreditation is proof that an engineering program meets the standards required to produce graduates capable of working in STEM education. Graduates from ABET-accredited programs have a concrete educational foundation and can play a dominant role in emerging technologies and innovation. ABET seeks to promote distinction in technical education by emphasizing continuous quality improvement processes, rather than prescribing methods [15]. A team of technical professionals and member societies developed the criteria for ABET accreditation. Regular program reviews are carried out by volunteers who have governmental, academic, and industry backgrounds. ABET program evaluators are trained to evaluate programs and perform program reviews for quality assessment. ABET accreditation ensures that students 
have acquired the proper education and provide prospects for the industry to guide the educational process concerning existing and future needs. The third-party peer review is essential in the technical fields where safety, precision, and quality are the most important aspects.

\section{Regional (NCAAA) institutional mechanical engineering program accreditation}

\section{Objectives of educational program}

The mechanical engineering program of Majmaah University has been designed to prepare students for a successful career. Graduates are expected to effectively apply problem-solving skills, critical thinking skills, and mechanical engineering knowledge in engineering and other domains such as business, medicine, and law. The second objective is that graduates continue their intellectual development through professional development and post-graduate education. The third objective is embracing leadership roles in mechanical engineering careers. Another goal is to complete professional engineering education and pursuit of advanced study and research in the mechanical engineering field. Further, graduates are expected to engage in alternative career choices.

The faculty of the mechanical engineering department of Majmaah University is one of the first to obtain accreditation from NCAAA. Figure 2a \& $2 b$ show the following years of continuous workload, having prepared self-studies, an external evaluator visiting the team, and the mechanical engineering program's commissioning performed following the official presentation to obtain accreditation. The faculty of mechanical engineering entered its final stage of accreditation. The engineering program identifies its intended learning outcomes and graduates attribute that are consistent with the mission and matches graduate attributes at the university level. The program's educational objectives are publicly disclosed, approved, and regularly reviewed.
A

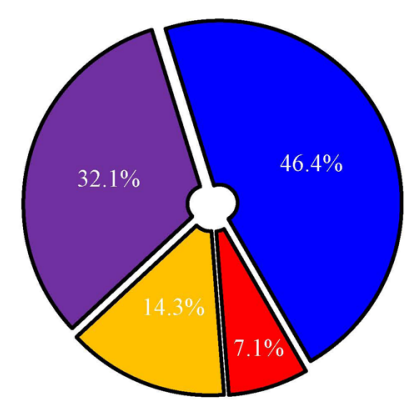

B

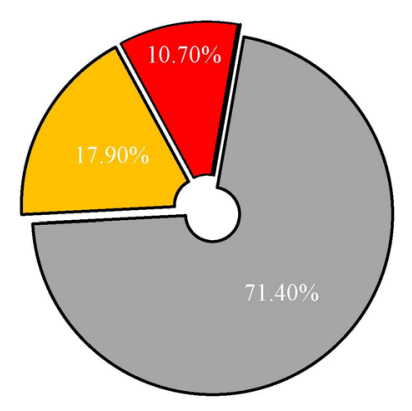

口Much lighter

口Too light

口Avrege

口Too havey

aMuch heavier

Figure 2: (a) Overall satisfied at ME program with a faculty member at MU; (b) the faculty workload at Mechanical Engineering program.

Table 2 shows the program outcomes associated with the ME program's course outcomes, while, resulting section validates one of the matrices for the selected courses numbering from 1-12. The educational objectives and learning results are in line with the country's qualification framework's standards and the labor market educational institutions' requirements. The program also identifies different learning outcomes for diverse tracks and applies suitable tools and mechanisms for measuring course objectives and graduate attributes. It verifies student achievement according to assessment plans and performance levels. There is a need for institutional commitment to the accomplishment of program objectives for achievement. Leadership at various departments is also involved in quality management and overseeing the quality assurance system. For instance, the Deans or Heads of Quality are responsible for the operation of procedures.

\section{Student outcomes}

Learning outcomes at the program level are precisely defined. They are in line with the requirements of the Saudi Arabia Qualifications Framework (SAQF) as well as related professional and academic standards and requirements of the labor market. In order to accomplish student learning outcomes, the curriculum must conform to professional requirements. The teaching faculty must implement effective and diverse learning and teaching strategies and assessment tools suitable for different learning outcomes. The attainment of learning outcomes is assessed through various means, and the results are utilized for continuous improvement. 


\section{Engineering Technology Open Access Journal}

Table 2: Mapping program outcomes associated with the course to outcomes of the educational program and the following sample.

\begin{tabular}{|c|c|c|c|c|c|c|c|c|c|c|}
\hline \multicolumn{11}{|c|}{ Map Course LOs with the Program } \\
\hline \multirow{2}{*}{ Course LOs \# } & \multicolumn{10}{|c|}{ ME Program Learning Outcomes } \\
\hline & a1 & a2 & b1 & b2 & b3 & c1 & c2 & c3 & d1 & d2 \\
\hline 1 & $\mathrm{x}$ & & $\mathrm{x}$ & & & & & & & \\
\hline 2 & & $\mathrm{x}$ & & $\mathrm{x}$ & & & & & & $\mathrm{x}$ \\
\hline 3 & & $\mathrm{x}$ & & & & $\mathrm{x}$ & & & $\mathrm{x}$ & \\
\hline 4 & & & & & & $\mathrm{x}$ & & & & \\
\hline 5 & & & & & $\mathrm{x}$ & & & $\mathrm{x}$ & & \\
\hline 6 & $\mathrm{x}$ & & $\mathrm{x}$ & & & $\mathrm{x}$ & & & & $\mathrm{x}$ \\
\hline 7 & & & & $\mathrm{x}$ & & & & & $\mathrm{x}$ & \\
\hline 8 & & & & & $\mathrm{x}$ & & & $\mathrm{x}$ & & $\mathrm{x}$ \\
\hline 9 & $\mathrm{x}$ & $\mathrm{x}$ & $\mathrm{x}$ & & & $\mathrm{x}$ & & & & \\
\hline 10 & $\mathrm{x}$ & & & & & & & & $\mathrm{x}$ & $\mathrm{x}$ \\
\hline 11 & & $\mathrm{x}$ & & & & & & & & \\
\hline 12 & & & $\mathrm{x}$ & & & & & $\mathrm{x}$ & & \\
\hline
\end{tabular}

The student educational outcomes of mechanical engineering programs include graduates' ability to apply information in solving practical problems. The second student outcome is the ability to design new experiments and the ability to understand and analyze data. The third outcome is the ability to design processes, apparatus, and systems to fulfill objectives. Another learning outcome is the ability to work effectively in multi-disciplinary contexts. The fourth learning outcome is the ability to establish, devise, and work out engineering problems. The fifth outcome is the ability to understand ethical and professional responsibility.

Another student outcome is the ability to communicate effectively via all means. Further, students should demonstrate an understanding of the effect of engineering outcomes in a societal and global context. Students should also show acknowledgment of the ability and the need to engage in lifetime learning. Finally, students should demonstrate current matters and utilize modern

engineering and computing tools, skills, and techniques.

\section{Assessment}

Assessment involves the process of appraising the academic standards of an institute against national NCAAA standards. Figure $3 \mathrm{a} \& 3 \mathrm{~b}$ demonstrate some of the common considerations taken into account during the evaluation process. These include the efficiency of training and teaching methods utilized by the organization in improving the skills and knowledge of its scholars [16]. It is particularly necessary that training and teaching should make the students ready for appropriate realworld application of their knowledge. Majmaah University always endeavors to achieve the highest quality research and learning based on NCAAA standards (Figure 3b). Efforts are being made to instill accreditation values in the common culture of students, administrators, faculty staff, and employees.

A

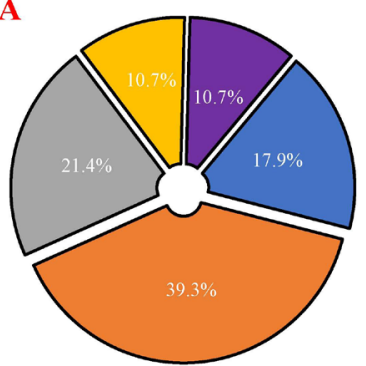

口6-9 Hours

口9-12 Hours

प12-15 Hours

पMore than 15 Hours

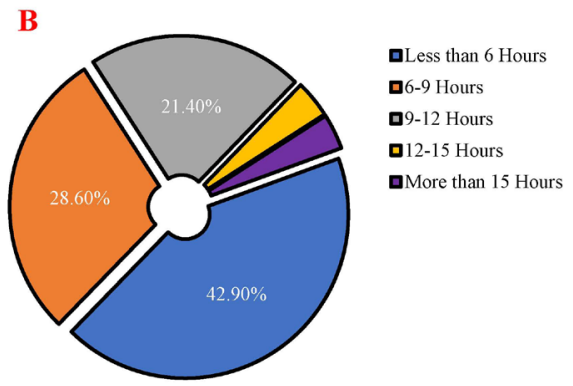

Figure 3: (a) Fulfilling administrative responsibilities/ committee work/ University service for1st Semester 2018; (b) Scholarship or conducting research (including writing, attending professional meetings for second semester 2019. 
The Department of Academic Accreditation conducts seminars and workshops for the teaching faculty, while students are introduced to the viewpoint fundamental to work in incorporated teams. Self-assessment of teaching is carried out based on NCAAA standards and has been accomplished by the mechanical engineering department. As a result, all the academic programs have been reviewed study plans and curricula have been updated [17]. Learners in the mechanical engineering program involved learning several courses in other departments, including English and Arabic languages, chemistry, physics, mathematics, Islamic culture, etc.

\section{Evaluation}

The programs of mechanical engineering are evaluated systematically. The assessment of the study programs of mechanical engineering departments is essential for the economy of Saudi Arabia. Quality is the cornerstone of state-of-the-art engineering education. Additionally, the expansion of higher education has increased the need to evaluate the institutions' national influence. Independent verification of standards relates to faculty, student accomplishments, and overall program. Performance assurance standards were associated with the overall program, faculties and student achievement can be obtained through a range of means such as monitoring of overall program, student knowledge survey, program appraisal survey, course assessment survey, and other student evaluation surveys.
The improvement planning can be done based on reflections obtained in teaching and learning, comprehensive action plans, interns' evaluations, employer satisfaction surveys, alumni satisfaction surveys, feedback advisory committee, internship satisfaction survey, assessment, and external examiners analysis. For Majmaah University, evaluation is a journey towards quality that is monitored through KPI s. It is considered as a means of tracking performance against objectives and goals. The university uses KPI to assess its current performance and guide action towards improvement and planning. The institution monitors KPIs as provided by NCAAA, and additional indicators are supplied and approved by the deanship of quality and accreditation at the organizational level.

Allactions required are typically undertaken by the department to ensure that courses fulfill the needs of students. The evaluation also seeks to establish whether courses are well-prepared and available to the program to ensure that they meet the program needs (Figure 4). Furthermore, during the program evaluation process, a review is carried out to guarantee that students in other departments are in line with the learning outcomes of the mechanical engineering programs [18]. The course reports and course specifications are assessed and collected for necessary improvement, which could be discussed through meetings with other departments.

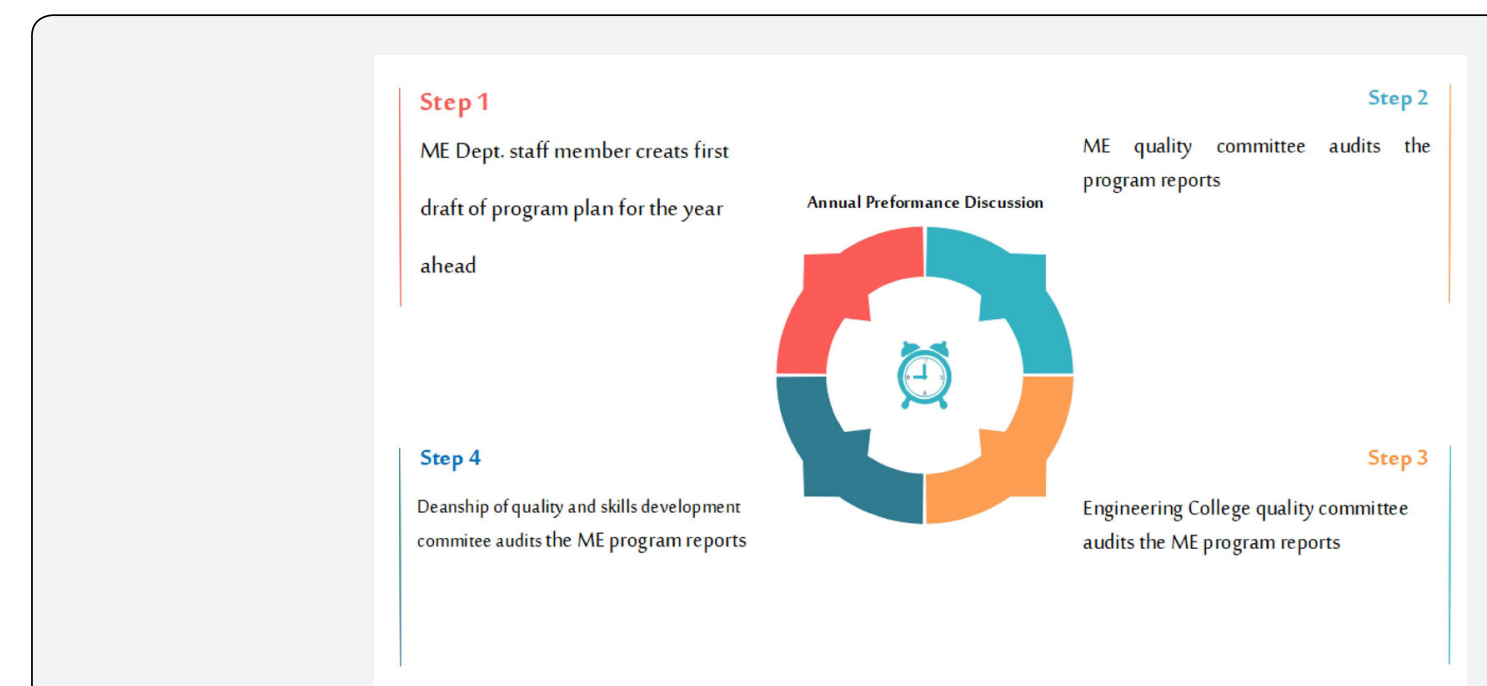

Figure 4: Mechanical engineering Dept. adopted the four-step approach to the annual academic performance development.

\section{Investigating international (ABET) institutional mechanical engineering}

\section{Objectives of the educational program}

ABET program's educational aims are extensively testimonials that illustrate what students are anticipated to accomplish within a limited time. Figure 5 shows the educational aims of the programs that are reflected in program constituencies. Institutions often have course educational objectives aligned with that of the university, the ABET criteria, and the different constituencies' needs. There should be an effective and documented process to follow during the program's learning objectives [19]. Educational objectives should be published, flexible, measurable, clearly defined, consistent with ABET criteria, needs of key constituencies, and reliable with the university's mission. 


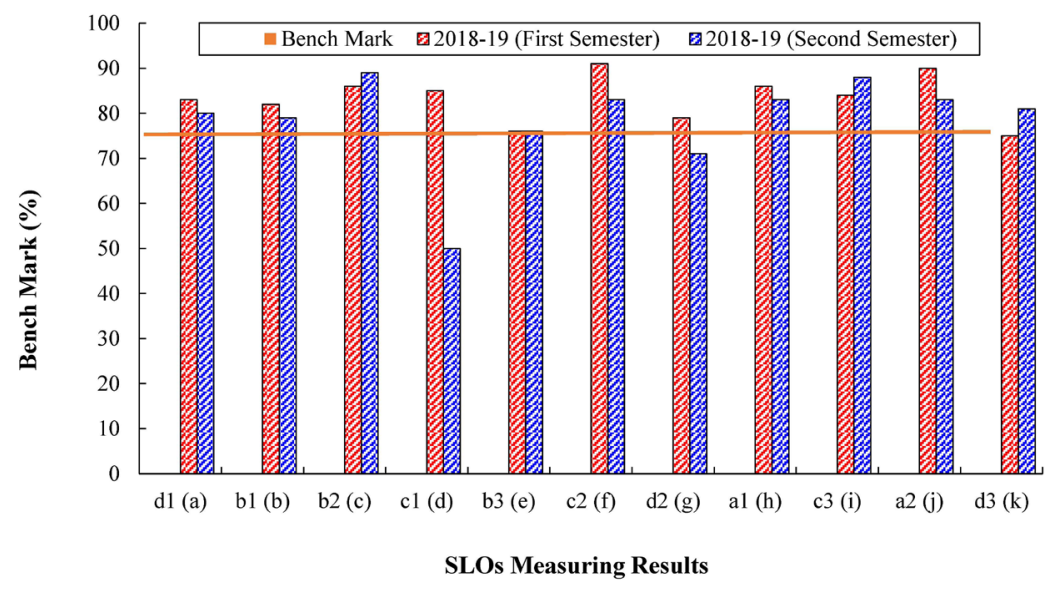

Figure 5: SLOs Measuring Results of First \& Second Semester 2018-19.

A specific process is required for determining and assessing the educational objectives of the program. The process should be a part of the broader evaluation of ABET criteria that provide the means to utilize the results of the assessment to enhance the program, provide regular evaluation, consider the mission of the institution, and provide a high level of connection with broad and relevant parts of the program. The ABET evaluators can have diverse views about the program, since each program is different. A shortlist of objectives is simpler to evaluate, as compared to a long list of objectives [20]. Typical objectives include involvement with professional and community organizations, passing a national proficiency exam, continuing to a graduate program, and employment within the profession [21]. The assessment of program objectives is critical to the accreditation and ABET focuses on program assessment. Discussion about the assessment, revision, and creation of program objectives should include faculty associated with the program, alumni of the program, students of the program, and external advisory board members.

The accomplishments and abilities of students after completing the program should be reflected in the objectives. Therefore, program objectives should be related to project outcomes. Program outcomes should state what students should accomplish during program completion (Almutairi, 2017) [22]. Additionally, objectives should flow naturally out of the stated mission.

\section{Student outcomes}

Student outcomes are one of the criteria of ABET. The accreditation of mechanical engineering degree programs include evaluating the program's assessment, and development to define the student outcomes. Learner outcomes refer to what students are expected to do by graduating [23]. The programs often document student results and arrange alumnae to accomplish the educational objectives [24]. Educational outcomes include the capability to work accordingly in multidisciplinary context and apply the skills and techniques of contemporary engineering. These outcomes are essential for engineering practices and for other purposes such as awareness of current issues, the ability to engage in life-long learning, and appreciate the influence of engineering concerning societal environmental, economic, and global contexts to consider ethical and professional responsibility. Students should also have the ability to recognize, create, and work-out engineering problems, design a system, process, or component to fulfill the objectives within rational limits associated with sustainability, manufacturability, health, and wellbeing as well as moral, political, collective, ecological, and economic repercussions of the objectives. This includes employing knowledge of engineering, science, and mathematics and analyzing and deducing data and skills to design and conduct experiments.

\section{Assessment}

One of the significant benefits of accreditation is that it is a continuous assessment process that lays the foundation for success. Assessment involves identifying, collecting, and preparing data to evaluate student outcomes. The practical assessment utilizes qualitative, quantitative, direct, and indirect tools to measure outcomes and objectives. Suitable sampling techniques may be used as a part of the evaluation process. Appraisal planning starts with the mission statement, representing the organization's purposes and other attributes that define an organization [25]. The assessment leader works with administrators and faculty to develop a timeline and plan of action to ensure that the departmental assessment deadlines and goals are met. The assessment offers a framework to establish, gather, and analyze data to assess the program's educational objectives and student outcomes.

The efficient evaluation uses appropriate direct, indirect, qualitative, and quantitative techniques suitable for measuring objectives or outcomes. Suitable sampling methods are essential parts of the assessment process. Effective and efficient assessment 
strategies call for an understanding of the alignment between strategies and practices. Therefore, mapping strategies are important for measuring learning outcomes. Data collection and analysis strategies should be consistent, systematic, and focused on assessing performance indicators.

The programs, as part of the accreditation initiative, assess the student performance. The evaluation process includes gathering and scrutinizing data to support a result. Institutions must demonstrate outcomes and objectives for the program being accomplished and measured. The assessment process should show how results are used for course advancement [26]. Documentation is essential, and keeping current records is important in availing current data. The suitability items, such as curriculum modifications and content revisions, should also be examined.

Table 3: Mechanical Engineering Program outcome assessment tools.
The evaluation methods are categorized into two major types: direct and indirect. A direct appraisal approach to assessing skills and knowledge can be challenging to achieve. Examination of students' work and observation is common to direct methods of assessment that are often utilized. Indirect approaches involve self-reporting techniques of the importance of learning experiences and are easier to realize. Since the indirect approach mostly relies on self-reporting and opinions, it is valuable [27]. A successful assessment process entails using both direct and indirect approaches, including a range of methods. There is no single method for evaluating a program. For many programs, evaluating the long-range objectives is clear-cut as the appropriate resource for thriving learners when applying their knowledge and skills in jobs (Table 3).

\begin{tabular}{|c|c|c|}
\hline Constituency & $\begin{array}{c}\text { Evaluation and Assessment } \\
\text { Instruments }\end{array}$ & Feedback Instruments \\
\hline Undergraduate students & Course survey & End of course Survey, informal feedback, and student discussion group \\
\hline Alumni & Alumni survey & Alumni survey and informal feedback \\
\hline Employers & Recruiter feedback, internship survey \\
\hline Paper Engineering Science Publications & Placement analysis & Foundation committees \\
\hline Majmaah University Administration & NA & Annual Faculty review \\
\hline Majmaah University Faculty & $\begin{array}{c}\text { Student work Exams, Course } \\
\text { portfolio }\end{array}$ & Faculty meeting \\
\hline
\end{tabular}

Some of the data sources used for quantitative assessment include student work, student co-op evaluations, and employers' co-op evaluation. Student coursework includes a quiz, multiplechoice examinations, long answer exams, homework, survey, lab, project, and presentation [14]. There can be many achievement levels, such as exemplary, exceeding, meeting standards, progressing towards standard, and below standards. Student assessment for each data source, outcome, and ABET (a-k) are then evaluated against an achievement benchmark.

The advisory board's input is also critical, especially if graduates are hired to work in different departments. A survey is one of the assessment tools that are commonly used, and they are kept as short as possible to improve the response rate. Surveys can be practical tools to keep in contact with employers and alumnae for relationship and development purposes. The assessment of program outcomes requires a significant amount of time and resources [28]. Students' knowledge in the classroom directly impacts program outcomes, while ABET does not define a specific course's results. Some courses have successfully relied on course grades, while others assess outcomes every time a course is taught.

\section{Evaluation}

Evaluation is a practice that involves the interpretation of data and evidence collected and analyzed during the assessment process. Table 4 demonstrates the NCAAA vs. ABET criterion to indicate that the application is to be filled for the ME program. The assessment determines the degree to which student outcomes are accomplished. Evaluation results in actions and decisions were regarding program enhancement. Further, it determines the level by which program educational objectives and student outcomes are accomplished [29]. Considerate evaluation of findings is critical to ensure that actions and decisions after the assessment process lead to program improvement. ABET evaluates the engineering degree of higher education institutions at the request of boards of engineers and institutions.

Applicants must fill out the application form for evaluation and pay a fee when applying for an assessment. Government, academia, and industry professionals play an essential role in their fields for ongoing improvements in quality engineering education [30]. ABET relies on experts' participation in making accreditation decisions, visiting campuses, and evaluating program materials. Evaluators having strong leadership abilities are promoted to the commission's ranks and are made responsible for serving leading teams of evaluators. Thousands of dedicated STEM practitioners from the government, industry, and academia form the core of the peer-based accreditation services [31]. The experts are the face of ABET. Figure 6 shows that technical professionals give their time and expertise to care about education quality and believe that the accreditation process enhances individual programs and student enrollment. 
Table 4: The checklist NCAAA vs. ABET criterion to indicate that the application is to be filled for the ME program.

\begin{tabular}{|c|c|c|c|c|c|}
\hline \multirow{2}{*}{ No. } & \multirow{2}{*}{ NCAAA Criteria Check List } & \multirow{2}{*}{ ABET Criteria Check List } & \multicolumn{3}{|c|}{ Audit Team Opinion } \\
\hline & & & Yes & No & Partial \\
\hline 1. & Program authorized & Program authorized & & & \\
\hline 2. & Request for Internal Audit approved & Assessment report (ABET Form) with approval. & & & \\
\hline 3. & $\begin{array}{l}\text { Program specification using the NCAAA template } \\
\text { (including program learning outcomes) }\end{array}$ & $\begin{array}{l}\text { Program specification using the ABET template } \\
\text { (including program learning outcomes) }\end{array}$ & & & \\
\hline 4. & Course specification using the NCAAA template & $\begin{array}{l}\text { Syllabus and Course specification using the ABET } \\
\text { template }\end{array}$ & & & \\
\hline 5. & $\begin{array}{l}\text { Descriptions of course and program requirements } \\
\text { and regulations }\end{array}$ & $\begin{array}{l}\text { Course Descriptions and program requirements } \\
\text { and regulations }\end{array}$ & & & \\
\hline 6. & $\begin{array}{l}\text { Annual course and program reports using the } \\
\text { NCAAA templates }\end{array}$ & $\begin{array}{l}\text { Annual course and program reports using the } \\
\text { ABET templates }\end{array}$ & & & \\
\hline 7. & $\begin{array}{l}\text { Summary report of student evaluation survey } \\
\text { results }\end{array}$ & $\begin{array}{l}\text { Summary report of student evaluation survey } \\
\text { results and Attendance }\end{array}$ & & & \\
\hline 8. & $\begin{array}{l}\text { Students graduated, evaluations by the students are } \\
\text { available }\end{array}$ & $\begin{array}{l}\text { Students graduated, assessment by the students } \\
\text { are available }\end{array}$ & & & \\
\hline 9. & Program advisory committee & Program advisory committee & & & \\
\hline 10. & $\begin{array}{l}\text { Institutional approved KPIs and benchmarks with } \\
\text { analysis }\end{array}$ & $\begin{array}{l}\text { Institutional approved KPIs and benchmarks with } \\
\text { analysis }\end{array}$ & & & \\
\hline 11. & Consistency with NQF & Head of Dept final approval & & & \\
\hline 12. & Self-evaluation scales are complete & Self-evaluation scales are complete & & & \\
\hline 13. & SSRP Self-Study Report for program & SSR Self-Study Report & & & \\
\hline
\end{tabular}

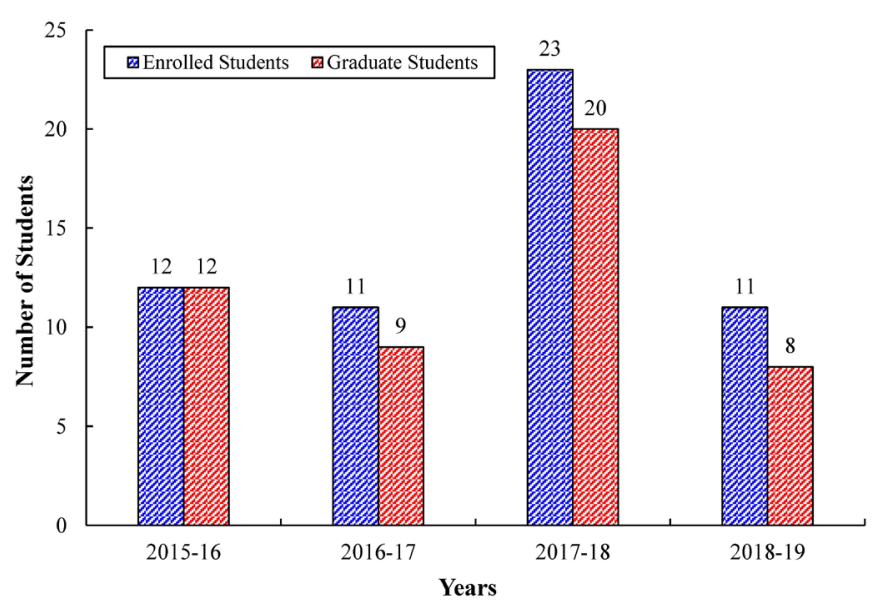

Figure 6: Shows enrolled management \& cohort analysis.

\section{Analysis of regional (NCAAA) institutional}

NCAAA is responsible for defining and standardizing academic accreditation and assessing institutions' programs throughout Saudi Arabia. Engineering education is pivotal to the progress of modern society. A method of confirming the high-quality engineering education is a thorough assessment undertaken by accreditation bodies such as NCAAA [32]. Majmaah University initiated external evaluations to recover the quality of mechanical engineering accessible. The commission is focused on evaluating, associating, and encouraging quality assurance processes of learning institutions to promote high-quality learning. The management of universities meets the highest global standards. Their levels of achievement and standards are widely recognized in Saudi Arabia and elsewhere in the world.

There are various principles that institutions have to observe during NCAAA accreditation. The first principle is that the quality obligation is of the institutions that deliver the program. Majmaah University and other institutions providing 
mechanical engineering programs are accountable for the quality of the programs offered and all the activities and facilities' quality. Institutional responsibility has various essential implications. One of the implications is that external organizations, including NCAAA, can assist in planning and implementing program improvement and evaluation strategies. These activities are not accountable to the university. An overseas organization can help, but it may not deliver quality. The university might regionalize some of its responsibilities or hand over authority to an inner unit such as a department; however, this practice does not completely exclude the university from its obligation. Evaluations conducted by NCAAA address everything that affects program quality during program accreditation.

For instance, when an organization in the country conveys a program that has been used or developed in another country, the Saudi institution will be responsible and accountable for the program quality. It is a common situation where a co-institution may observe technical and academic qualifications in a different country. An international college or university needs to meet the quality requirements for an institution of its type in the country if it is looking forward to establishing a legal entity within Saudi Arabia irrespective of any quality requirements and accreditation in its own country. It should provide adequate facilities and resources within Saudi Arabia to fulfill quality standards.

The second principle involves all quality parameters that specify an institution's purposes and accomplishments. In universities, quality assurance processes involve educational programs and include equipment and facilities, community relationships, enrollment, and administrative and organizational matters. Outcomes, processes, and involvements are considered within the inside units' individual with a specific focus on the quality of the outcomes.

The thirdprincipledealswith the supportfor continuousquality improvements instead of satisfying set standards. A significant objective of NCAAA quality assurance and accreditation is incessant development. The orientation permeates all activities of NCAAA. Program assessment is based on the primary assumption that universities and colleges wish to increase and high-quality levels to meet international standards. The essential function of NCAAA is assisting universities in accomplishing developments [24]. An essential consideration during the accreditation evaluation is the availability and effective implementation of quality improvement mechanisms. Universities encourage continuous improvements beyond the minimum requirements in all activities. NCAAA has a constitutional responsibility to ensure that necessary standards are accomplished. Specifically, accreditation ensures that the standards are either met or surpassed.

The fourth principle deals with the supportive relationships between institutions, NCAAA, and reviewers. No program or university can be considered as completely improved as there is always an opportunity for improvements. The willingness to acknowledge mistakes and weaknesses is a strength and not a weakness [30]. People and groups within learning institutions can acknowledge gaps and make plans to bridge them without fear of destruction. The relationship and interactions between universities and the NCAAA should be cooperative, open, and transparent. Another principle is that quality must be independently verified [33]. The conclusion about the quality does not rely on subjective judgment; instead, it relies on observable evidence. Attainment evidence should be identified beforehand, and benchmarks are identified to help establish appropriate standards systematically.

NCAAA encourages diversity as the flexibility of how organizational arrangement occurs in meeting diverse societies' needs and dealing with opposite circumstances and missions. Permitting diversity is also essential if innovation and creativity are encouraged and improved over time. Different universities have different needs to meet the criteria. For instance, innovation may be a critical component of some programs and institutions as compared to others. The extent of interaction of institutions with their stakeholders varies from one institute to another. However, the quality of outcomes expected for the accreditation award does not vary; however, there are alterations in specific standards' expectations. It is possible to rely on unswerving student standards outcomes without considering the institution the students attend and the institution's programs only if community self-confidence in mechanical engineering is to be preserved.

NCAAA also operates on the principle that stakeholders' involvement should be substantial in the planning and reviewing of feedback. Members of the community, providers of funds, employers, staff, graduates, and students are served by any other group associated with the university. Stakeholders have to be involved, but their perspective is also considered an effective quality assurance system. The quality obligations were improvement of an institution that can be achieved through widespread involvement and effective leadership. All faculties are focused on the evaluation of the performance of units within which they work. Plans and concepts should be offered following evaluation [34]. There should be effective coordination and leadership at the institutional level. Coordination and administration should be collective with reporting, planning, assessment, and participation, while effective leadership is critical; similarly, administrative and academic units must coordinate their efforts.

\section{Analysis of international (ABET)}

The engineering faculty has gone through adopted longterm planning and development strategies to meet the ABET's accreditation process. Members of the societies who are the part of ABET nominate and appoint members of the board of directors, board-level councils, and accreditation commissions. The organization has been providing quality assurance and accreditation services for 80 years. It is linked to thousands of programs and hundreds of universities and colleges worldwide [4]. The process was planned to ensure that suggestions of 
available programs are equivalent to the mechanical engineering programs' international standards. Additionally, programs must fulfill the requirements of graduates as well as society.

ABET accreditation is qualified charitable machinery for engineering programs that is controlled by specialized groups. The process helps universities to make a constructive transfer towards certified legitimacy. ABET is considered as a highly respected institution involved in the accreditation of engineering programs. Institutions that offer mechanical programs are bound to make significant changes on account of intense global competition. ABET announced new Engineering Criteria 2000 to signify the value of engineering education curriculums by emphasizing the evaluation and assessment process that guarantees to accomplish a set of educational outcomes and objectives. An essential component of these standards is the initiation of the incessant development process through outcomes assessment. Figure 7a shows the faculty load in teaching per semester during 2018-2019. The old course credits classification was significantly deserted and substituted with an outcomes-based procedure [35]. The outcome-based assessment process focuses on the learning outcomes before and after completion. ABET integrates conventional soft skills and complex engineering skills in its accreditation principles. Soft skills include engineering, ethics, professionalism, teamwork, communication, knowledge of contemporary issues, lifelong learning, and engineering concerning the societal and global context.
A

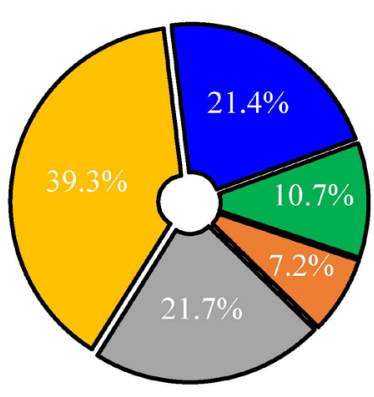

B

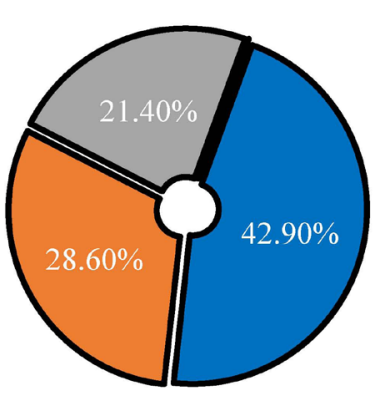

DLess than 6 Hours

ש6-9 Hours

-9-12 Hours

-12-15 Hours

DMore than 15 Hrs.

Figure 7: (a) Parentage of faculty spending more than 12 hrs. a week in teaching is high; (b) Scholarship or conducting research (including writing, attending professional meetings.

It is important for the institutions that the graduates accomplish appropriate levels of the required skills. Understanding and determining student outcomes and learning experiences are critical for satisfying accreditation agencies and continuous improvement. Additionally, the planning and execution of educational programs should be consistent with the educational objectives and outcomes of program accomplishment and the engineering department's mission. On the other hand, educational programs promote continuous improvement to enhance their ability to fulfill the program's components as the requirements are fulfilled, and program outcomes and objectives are improved (Figure 7b).

In accomplishing ABET standards, engineering programs can face a range of challenges. The most challenging issues include the establishment of program outcomes and program educational objectives. Objectives often go through various trials and changes and are accomplished by the program [36]. The university program committee formulated a range of objectives for mechanical engineering programs. The first objective is that mechanical engineering graduates have the knowledge and skills necessary for carrying out an inspection, maintenance, operation, installation, and design of energy and mechanical systems.
The second objective is utilizing modern-experimental techniques and information technology, computational, mathematical, and data analysis tools to solve problems. The third objective is that the students should fit in a range of working environments as they can work in multidisciplinary teams with effective communication skills. Further, students should be involved in lifetime education and achievement skills to enhance career planning and professional improvement based on professional and social ethics [37]. Another program objective deals with the evaluation to recognize that all the objectives considerably reflect the program requirements. Majmaah University's mechanical engineering department modified its academic programs to be consistent with the new classification. During the time, the mechanical engineering program's educational outcomes were initiated by the mechanical engineering department's faculty in agreement with the existing components.

The mechanical engineering program of Majmaah University is based on a combined range of strategies targeted at identifying and executing a designed procedure that demonstrates educational purposes translated into measurable performance standards, measurable outcomes, and response pathways for remedial activities. The mechanical engineering section devised program 
objectives in order to meet all ABET criteria. Additionally, a new technical result was complementary to the available ABET results. Program objectives were presented to a range of element groups to obtain their review and comments. The mechanical engineering course product is available on the university's website and in the student handbook. One of the key attributes of the ABET program is the continuous improvement process. The planning and implementation of the outcome process call for the compilation, analysis, and use of data about courses to determine enhancement in student learning and improvement.

In this context, the mechanical engineering department offers the required evaluation training on planning, reviewing key institutional practices, identifying and creating assessment tools, and organizational practices to ensure alignment with the evaluation process. The department has an assessment plan that follows a conceptual model and is utilized in the engineering departments. Figure 8 shows the procedure involved in the application of the "Plan-Do-Check-Act." The plan has two interrelated loops: the fast loop and the slow circle, where the mechanical engineering department assesses its program outcomes. In the early years of the assessment procedure, the mechanical engineering department revised its course outcomes and program outcomes each year [38]. In recent years, the course and program outcomes have correctly manifested the existing purposes.

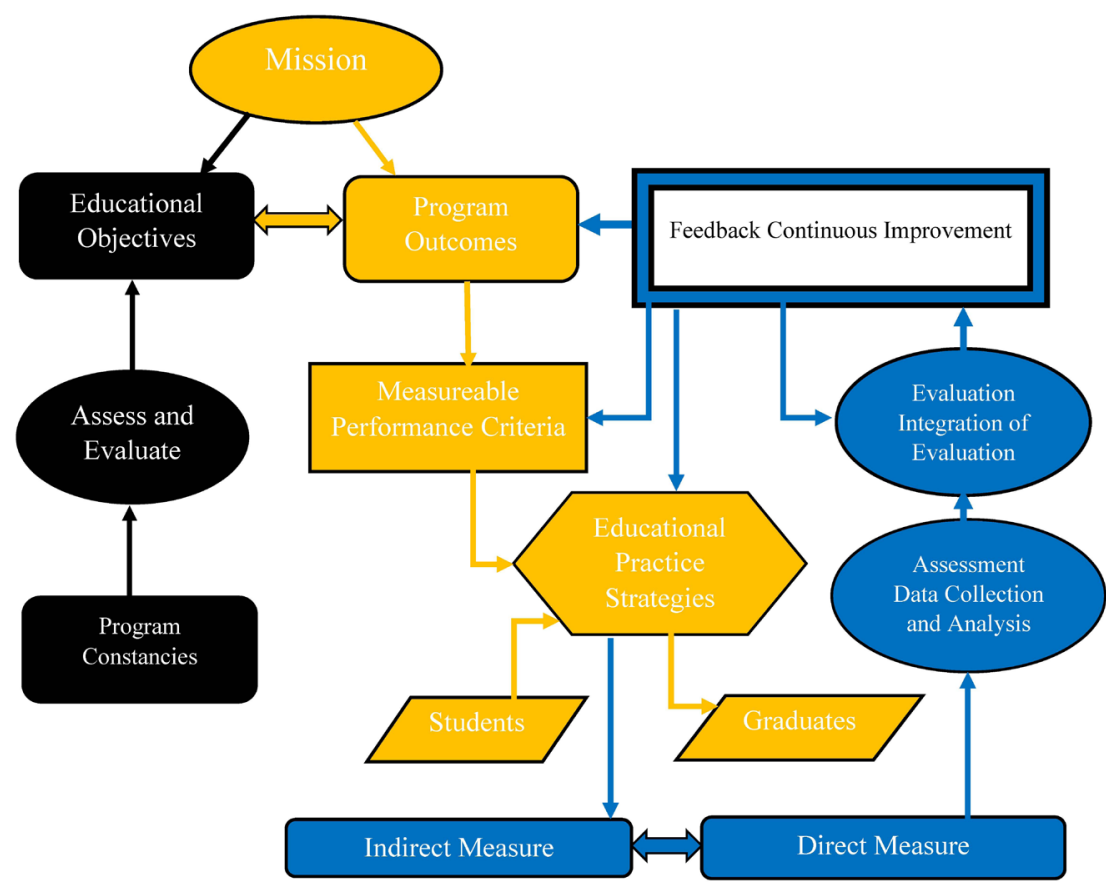

Figure 8: Flow chart of ME process mechanical engineering department assesses its program outcomes.

Table 5 shows that the course outcomes and program outcomes are often reviewed and updated after a few years to reproduce the curriculum adjustments. In the fast loop, the assessments of the degree to which graduates, and students accomplish program objectives reflected in the slow circle are shown. Data is collected each year and summed up by the examination committee in an evaluation report. The evaluation outcomes are then analyzed by the mechanical engineering subject committees [39]. Any recommendations and conclusions drawn are included in the report. Conclusions and results can be obtained from the mechanical engineering committee.

Curriculum modifications to retain the program's cost lead to the instigation of easy for deploying evaluation plans for ensuring minimal overload on faculty contributing to evaluation exercises. A culture of evaluation or a strong interest in accreditation initiatives among faculty is dependent on the progression of effective evaluation frameworks for evaluation to be successful. The overall evaluation exercise's success is merely possible if the plans for evaluation data collection, its examination, and integration of the outcomes are connected with the institution's environment and culture. It must be considered vital for having accurate evaluation data to close the evaluation loop and identify where modifications in the programs are needed. On the contrary, integrating the suggested changes must be stated and easy for executing the overall exercise. The workshops were quite obvious and assisted in developing, planning, and executing the assessment strategies. 
Table 5: Approval criteria of the program Learning Outcomes Courses in the Mechanical Engineering Dept.

\begin{tabular}{|c|c|c|c|c|c|}
\hline $\begin{array}{c}\text { ABET } \\
\text { Domain }\end{array}$ & $\begin{array}{l}\text { NCAAA } \\
\text { Domain }\end{array}$ & $\begin{array}{c}\text { Program Learning Outcomes } \\
\text { Courses }\end{array}$ & & & ME Program KPIs \\
\hline \multirow{7}{*}{$a$} & \multirow{7}{*}{ A } & \multirow{2}{*}{$\begin{array}{l}\text { Ability to apply knowledge of math- } \\
\text { ematics, science, and engineering }\end{array}$} & KPI1 & KPI1 & $\begin{array}{l}\text { Apply mathematical and scientific principles to formulate } \\
\text { models and systems relevant to civil engineering. }\end{array}$ \\
\hline & & & KPI2 & & Understanding Mechanical engineering theoretical concepts. \\
\hline & & & & KPI2 & $\begin{array}{l}\text { Explain engineering problems by using the concepts of inte- } \\
\text { gral and differential calculus and linear algebra. }\end{array}$ \\
\hline & & & & KPI3 & $\begin{array}{l}\text { Suitable engineering interpretation of mathematical and } \\
\text { scientific terms. }\end{array}$ \\
\hline & & & KPI3 & KPI4 & Translating academic theory into engineering applications. \\
\hline & & & KPI4 & KPI5 & Performing calculations correctly. \\
\hline & & & & KPI6 & Examining data using statistical concepts \\
\hline \multirow{10}{*}{$\mathrm{c}$} & \multirow{10}{*}{ B } & \multirow{7}{*}{$\begin{array}{l}\text { Ability to design a system, compo- } \\
\text { nent, or process to meet desired } \\
\text { needs within realistic constraints } \\
\text { such as economic, environmental, } \\
\text { social, political, ethical, health } \\
\text { and safety, manufacturability, and } \\
\text { sustainability }\end{array}$} & KPI9 & KPI16 & Build Up a design strategy \\
\hline & & & & KPI17 & Apply of approaches \\
\hline & & & & KPI18 & Improving solutions \\
\hline & & & & KPI19 & $\begin{array}{l}\text { Understanding how areas interrelate and demonstrate the } \\
\text { ability to integrate prior knowledge into a new problem }\end{array}$ \\
\hline & & & KPI10 & KPI20 & Using computer engineering tools \\
\hline & & & & KPI21 & $\begin{array}{l}\begin{array}{l}\text { Supportive design procedure with documentation and } \\
\text { references }\end{array} \\
\text { (n) }\end{array}$ \\
\hline & & & KPI11 & KPI22 & Developing a solution that includes realistic constraints. \\
\hline & & & KPI12 & KPI23 & $\begin{array}{c}\text { Applying engineering and scientific principles correctly to } \\
\text { design practical processes }\end{array}$ \\
\hline & & & & KPI24 & $\begin{array}{c}\text { Identifying the practical significance of design outcome/ } \\
\text { answer }\end{array}$ \\
\hline & & & & KPI25 & Thinking holistically \\
\hline \multirow{9}{*}{$\mathrm{e}$} & \multirow{9}{*}{ B } & \multirow{4}{*}{$\begin{array}{l}\text { Ability to identify, formulate, and } \\
\text { solve engineering problems }\end{array}$} & & KPI36 & Solutions creativity alternatives \\
\hline & & & KPI17 & KPI37 & Practical problem solving using theoretical concepts \\
\hline & & & KPI18 & KPI38 & Predict and defend problem outcomes \\
\hline & & & KPI19 & KPI39 & The uses of appropriate resources needed to solve problems \\
\hline & & & & KPI40 & The integration of new information with previous knowledge \\
\hline & & & & KPI41 & $\begin{array}{l}\text { The understanding of how various pieces of the problem } \\
\text { relate to each other and the whole }\end{array}$ \\
\hline & & & KPI20 & KPI42 & Strategies for solving problems \\
\hline & & & & KPI43 & Modification of the answer \\
\hline & & & & KPI44 & Solutions: other ways \\
\hline \multirow{8}{*}{$\mathrm{g}$} & \multirow{8}{*}{$\mathrm{D}$} & \multirow{3}{*}{ Ability to communicate effectively } & & KPI52 & Articulation of ideas \\
\hline & & & KPI25 & KPI53 & The association of the written materials \\
\hline & & & KPI26 & KPI54 & The utilize of graphs, tables, and diagrams \\
\hline & & & & KPI55 & The lecture of the written work \\
\hline & & & KPI27 & KPI56 & Writing, Grammar, and spelling \\
\hline & & & & KPI57 & PowerPoints formatting \\
\hline & & & & KPI58 & Writing technique \\
\hline & & & & KPI59 & Proposed format (if applicable) \\
\hline
\end{tabular}


The subject committee members consider necessary modifications in courses before they can be implemented in courses. The subject committee members are course arrangers in the mechanical engineering courses. Appreciated modification is offered by the course supervisor to the course assembly and debated in a committee consultation. The course supervisor then discusses the implementation of changes with the current course instructor. Recommendations that may be presented in the assessment report can be implemented in the curriculum. The subject committees discuss any curriculum changes. Later, any detailed course alteration proposal is crafted and presented to the concerned committee for evaluation and then offered to mechanical engineering faculty for approval. The large loop has been cut down in the assessment plan and terminologies presented in a simple way that all faculty and component members understand.

Opportunities are created through the adoption of the ABET accreditation model to review periodically and update the curriculum and stimulate the integration of innovations in the teaching methods and curriculum. These enablers allow programs for identifying which requirements are incorrect; the course syllabus is outdated, redundancies between classes, reassess the lab sessions and complementary courses, and courses that are no longer on-demand, among other concerns. The modifications can take place in the curricular contents, facilities, educational plans, assessment practices, and activities. Another benefit of ABET accreditation is integrating feedback procedures from external and internal stakeholders about the program curriculum's appropriateness. The evaluation process must explore whether a program is fulfilling the discipline's requirements or whether curriculum changes should be made. ABET develops quality standards based on the requirements of each profession and via professional and technical communities. Students can explore global employment options or academic opportunities for continuing education with the curriculum consistent with international requirements.

On the contrary, some embarrassments occur with any significant curriculum change that must be conducted throughout the Majmaah education system since these modifications must follow a tedious and long process for official approval. In particular, this curriculum modification process executes slowly as compared to the continuous update experienced by profession. Besides, a challenge is revealed through the accreditation process in several public universities since there is a lack of culture for encompassing professional bodies in the reviewing process. The curriculum has been investigated merely from the academic viewpoint.

\section{Conclusion}

Several countries have adopted ABET accreditation, and employers internationally recognize the value of ABETaccredited programs. NCAAA was established in Saudi Arabia to determine criteria and standards for academic assessment and accreditation. The commission focuses on higher studies institutions' quality assurance procedures to ensure that educational institutions' management and quality follow the highest international standards. Engineering programs in Saudi Arabia compete to obtain the most internationally recognized accreditation system that focuses on students' achievements and teaching quality. Mechanical engineering program mapping noticed no understanding or awareness of professional and ethical responsibility, indicating that the ME curriculum has no ethical courses. Several advantages and opportunities were noted in this study. For example, the continuous enhancement system was adopted, and integration. The quality culture in engineering education was promoted through ABET accreditation. The constant enhancement process allocates the program's educational objectives, student outcomes, institutional mission, curricula, and evaluation methods. Therefore, programs become more aware of their institutional mission and their major stakeholders, such as employers, faculty, students, alumni, funding sources, and program graduates. Another advantage is that productively preserving an evaluation culture compared to the summative one is the most significant pattern learned via the accreditation process. Assessment Outcomes culture fulfilled a continuous enhancement philosophy, making it possible for making adequate decisions based on sound documented evidence. On the other hand, there are some disadvantages and barriers. The main issue is the high cost of adapting and preparing programs for fulfilling the ABET accreditation pre-requisites. Time and effort are required in accreditation to be significant, which can sometimes drive elevated workloads and time pre-requisites, lack of faculty commitment, and inappropriate training. Another obstacle was the lack of a systematized, structured and functional enhancement process approved by the engineering program's faculty members. In particular, there are no established and formal policies for the enhancement process; therefore, such activities are assumed supplementary or additional activities regardless of the specific weight in the academic procedures. In Saudi Arabia, implementing the additional accreditation standard sometimes becomes complicated concerning the existing national accreditation process. It requires institutional support, an open mind, and more resources for promoting the quality assurance of engineering education. Lastly, this initiative to identify what an international accreditation process brings opportunities and barriers enables institutions, civil society, and programs to be conscious of the significance in linking with the elements, current requirements, and professional skills of the program for successfully performing in a global context.

\section{References}

1. Dodridge M (2002) Recognition and accreditation of 'short cycle' degrees in engineering. European Journal of Engineering Education 27(4): 307-323.

2. Szanto TR (2005) Evaluations of the third kind: external evaluations of external quality assurance agencies. Quality in Higher Education 11(3): 183-193. 
3. Young KE (1983) Understanding Accreditation: Contemporary Perspectives on Issues and Practices in Evaluating Educational Quality. Jossey-Bass, Inc., 433 California St., Suite 1000, San Francisco, CA 94104.

4. Francis F (2016) Engineering approach with quality function deployment for an ABET accredited program: a case study. American Journal of Mechanical Engineering 4(2): 65-70.

5. El Bawab TS (2015) Telecommunication engineering education (TEE): Making the case for a new multidisciplinary undergraduate field of study. IEEE Communications Magazine 53(11): 35-39.

6. Echeverri CJO, Reséndiz JR, Aparicio MG (2018) An approach to STFT and CWT learning through music hands-on labs. Computer Applications in Engineering Education 26(6): 2026-2035.

7. Al Yahya SA, Abdel halim MA (2013) A Successful Experience of ABET Accreditation of an Electrical Enginnering Program [versión electrónica]. IEEE Transactions on Education 56(1): 165-173.

8. Al Junaid H, Almeer M, Khlaifat J, Bushager A (2019) Developing a computer engineering undergraduate curriculum: the challenges and solutions. Global Journal of Engineering Education 21(1): 45-53.

9. Rabaai A, Rababaah AR, Al Maati SA (2018) Comprehensive guidelines for ABET accreditation of a computer science program: the case of the American University of Kuwait, International Journal of Teaching and Case Studies.

10. Rabaai AA (2017) The use of UTAUT to investigate the adoption of e-government in Jordan: a cultural perspective. International Journal of Business Information Systems 24(3): 285-315.

11. MacKinnon JG, Webb MD (2016) Difference-in-differences inference with few treated clusters (No. 1355). Queen's Economics Department Working Paper.

12. Shafi A, Saeed S, Bamarouf YA, Iqbal SZ, Min Allah N, et al. (2019) Student outcomes assessment methodology for ABET accreditation: A case study of computer science and computer information systems programs. IEEE Access 7: 13653-13667.

13. Sameh A, Khan F, El Hakim N A Framework for Judging Processes for Quality Assessments of Program-Level Accreditation. In Smart Learning Conference Proceedings, p. 134.

14. Taleb A, Namoun A, Benaida M (2019) A Holistic Quality Assurance Framework to Acquire National and International. Journal of Engineering and Applied Sciences 14(18): 6685-6698.

15. Ibrahim Y, Akhter F, Albalawi W (2016) The Accreditation Dilemma: A Case Study of Adoption of Structured Web-Based Accreditation Systems in Saudi Arabian Higher Education Environment. Journal of Administrative Sciences 27(1): 19-27.

16. Al Baity H, Alsaeed DH, Bayoumi S, Al Twairesh N, Al Khalifa H (2018) Rejuvenation of the IT Program at King Saud University: A Change Reflecting Local and Global IT Trends. In Proceedings of the 19th Annual SIG Conference on Information Technology Education, pp. 129134

17. Al Murtadha Y (2018) Public Response Sentimental Analysis Model to Review Educational Program Seeking Academic Accreditation. In Proceedings of the 2018 International Conference on Computers in Management and Business, pp. 83-87.

18. Brahimi T, Sarirete A, Ibrahim RM (2016) The Impact of Accreditation on Student Learning Outcomes. International Journal of Knowledge Society Research (IJKSR) 7(4): 51-62.

19. Aoudia M, Al Qahsi DADA (2015) Development of a new curriculum for an industrial engineering program that meets the curriculum requirements of $\mathrm{ABET}$ and the institution. In 2015 IEEE Global Engineering Education Conference (EDUCON). IEEE, pp. 151-158.
20. Dantley S, Maffet G (2016) Academic Accreditation in Saudi Arabia: The Future-Quality Assurance and Accreditation for Academic Institutions. In Teacher Quality and Teacher Education Quality, Routledge, pp. 212-236

21. Alkahtani MS, El Sherbeeny AM, Abdullah FM (2018) Assessing Engineering Minorities in Saudi Arabian Higher Education: Status and Challenges.

22. Almutairi M (2017) A Comparative Study of ABET Accredited Associate Degree Programs, Evidence from Saudi Arabia. Business Education \& Accreditation 9(1): 65-81.

23. Albaqami S (2019) Strategic Analysis for Accreditation in Saudi Arabia: A Cross-Case Analysis of KAU and PSU. Education Quarterly Reviews $2(4)$

24. Bhatti A, Ahmed I (2015) Academic Diversity and Assessment Process for CS Program Accreditation. Creative Education 6(08): 773.

25. Brahimi T, Sarirete A, Khalifa S (2018) Impact of Accreditation on Engineering Education. In Enhancing Knowledge Discovery and Innovation in the Digital Era. IGI Global, pp. 91-106.

26. Huque ASA (2015) Concurrent application for ABET and NCAAA accreditation. In Southeast Con 2015. IEEE, pp. 1-7.

27. Sait HH, Turkman N, Ishaq R (2018) Managing the Senior Capstone Design Project for Undergraduate Students at King Abdulaziz University. International Journal of Engineering Pedagogy (IJEP) 8(5): 89-107.

28. Chalisserry EP, Nam SY, Anil S (2017) Effect of Silicone-Doped Hydroxyapatite on Bone Regeneration and Osseointegration: A Systematic Review. Journal of Biomaterials and Tissue Engineering 7(12): 1209-1218.

29. Marey M, Ibrahim YE, Ruiz ESC (2018) Integrated assessment of course and program learning outcomes for accreditation process. In 2018 IEEE Global Engineering Education Conference (EDUCON). IEEE, pp. 175-182.

30. Aoudia M, Abu Alqahsi DAD (2015) Curriculum redesign process for an industrial engineering program seeking ABET accreditation. International Journal of Engineering Pedagogy (IJEP) 5(3): 45-52.

31. Faiz MMU, Al Mutairi MS (2015) Engineering education for a resilient society: A case study of the kingdom of Saudi Arabia. In 2015 International Conference on Interactive Collaborative Learning (ICL). IEEE, pp. 82-88.

32. Khan MI, Mourad SM, Zahid WM (2016) Developing and qualifying Civil Engineering Programs for ABET accreditation. Journal of King Saud University-Engineering Sciences 28(1): 1-11.

33. Al Yahya S, Abo elnasr AA (2017) ABET Accreditation Experiences in Department of Mechanical Engineering, College of Engineering, Qassim University, Staff and Educational Development International (ISSN: 0971-9008) 16: 129-144.

34. Bubacz M, Rabb R, Howison J, Skenes K (2016) Introducing a Tool for ABET Course Assessment (ACA) for a New Engineering Program. In ASEE Southeast Section Annual Conference, ASEE.

35. Liu Y (2017) Renovation of a mechanical engineering senior design class to an industry-tied and team-oriented course. European Journal of Engineering Education 42(6): 800-811.

36. Bubacz M, Rabb R, Howison J, Skenes K, Bass P, et al. (2017) ABET program assessment (APA) for a new engineering program. In Proc. 2017 ASEE Zone 2 Conf, pp. 2-5.

37. Ro HK, Merson D, Lattuca LR, Terenzini PT (2015) Validity of the contextual competence scale for engineering students. Journal of Engineering Education 104(1): 35-54. 
38. Robinson R, Hensel Jr E (2015) A process for assessment of ABET student outcomes in a mechanical engineering department. In 13th LACCEI Annual International Conference: "Engineering Education Facing the Grand Challenges, What Are We Doing, pp. 29-31.
39. Uziak J (2015) Position of the final year project in an engineering curriculum. Global Journal of Engineering Education 17(3): 113-118.

Commons Attribution 4.0 License
DOI: 10.19080/ETOAJ.2021.03.555621

\author{
Your next submission with Juniper Publishers \\ will reach you the below assets \\ - Quality Editorial service \\ - Swift Peer Review \\ - Reprints availability \\ - E-prints Service \\ - Manuscript Podcast for convenient understanding \\ - Global attainment for your research \\ - Manuscript accessibility in different formats \\ ( Pdf, E-pub, Full Text, Audio) \\ - Unceasing customer service
}

Track the below URL for one-step submission https://juniperpublishers.com/online-submission.php 